\title{
Estimates of neonatal morbidities and disabilities at regional and global levels for 2010: introduction, methods overview, and relevant findings from the Global Burden of Disease study
}

\author{
Hannah Blencowe ${ }^{1}$, Theo Vos ${ }^{2,3}$, Anne CC Lee ${ }^{4,5}$, Rachel Philips ${ }^{6}$, Rafael Lozano ${ }^{2}$, Miriam R. Alvarado', Simon Cousens ${ }^{1}$ \\ and Joy E. Lawn ${ }^{7,8}$
}

BACKGROUND: Neonatal mortality and morbidity are increasingly recognized as important globally, but detailed estimates of neonatal morbidity from conditions and longterm consequences are yet to be published.

METHODS: We describe the general methods for systematic reviews, meta-analyses, and modeling used in this supplement, highlighting differences from the Global Burden of Disease (GBD2010) inputs and methods. For five conditions (preterm birth, retinopathy of prematurity, intrapartum-related conditions, neonatal infections, and neonatal jaundice), a standard three-step compartmental model was applied to estimateby region, for 2010 - the numbers of (i) affected births by sex, (ii) postneonatal survivors, and (iii) impaired postneonatal survivors. For conditions included in GBD2010 analyses (preterm birth and intrapartum-related conditions), impairment at all ages was estimated, and disability weights were applied to estimate years lived with disability (YLD) and summed with years of life lost (YLL) to calculate disability-adjusted life years (DALYs). RESULTS: GBD2010 estimated neonatal conditions (preterm birth, intrapartum-related, neonatal sepsis, and "other neonatal") to be responsible for 202 million DALYs or 8.1\% (7.3-9.0\%) of the worldwide total. Mortality contributed $95 \%$ of the DALYs, and the estimated $26 \%$ reduction in neonatal condition DALYS since 1990 is primarily due to a $44 \%$ reduction in neonatal mortality rate due to these conditions, counterbalanced by increased numbers of babies born (17\%). Impairment following neonatal conditions remained stable globally and is therefore relatively more important, especially in high- and middleincome countries. Crucial data gaps were identified.

CONCLUSION: These results confirm neonatal conditions as a significant burden, reemphasizing the need to reduce deaths further, to count the linked 2.6 million stillbirths, and to better measure and address their long-term effects.

n 2011, around 135 million babies were born alive worldwide, and an estimated 3 million of these died during the first $28 \mathrm{~d}$ of life $(1,2)$. During the past decade, some progress has been made in reducing neonatal mortality, but this progress has been slower than that for postneonatal (1-59 mo) and maternal mortality $(2,3)$. Reducing neonatal deaths is increasingly being recognized as a public health priority largely because of the Millennium Development Goal 4-to reduce under-5 mortality by twothirds between 1990 and 2015 (Figure 1) (3). Neonatal deaths now account for more than $43 \%$ of child deaths below $5 \mathrm{y}$ of age.

The slower progress in reducing newborn deaths brings these deaths to the top of the child mortality agenda moving into the post-Millennium Development Goal era $(4,5)$. Widespread disparity in neonatal mortality exists both between and within individual countries, in many cases with substantial variation between regions and by socioeconomic class (6). Unlike many other child health issues, neonatal conditions, and particularly preterm birth, are associated with an important burden in highincome countries (7). Advances in neonatal care since the 1970s have improved the survival of even the most vulnerable babies, for example, those born preterm before 28 completed weeks and those with severe congenital abnormalities. However, these survivors remain at risk of long-term sequelae (8).

Systematic national estimates of causes of neonatal mortality have been important in linking the large number of newborn deaths to programmatic solutions and action $(3,9,10)$. However, neonatal morbidity and its long-term impact on health and impairment have received much less attention and are increasingly important issues for individuals, families, and nations. To date, no systematic estimates of disability have been undertaken $(1,10,11)$. As focus shifts to the post-Millennium Development Goal agenda, increasing recognition is being given to disabilityfree survival, human capital, and sustainable development.

The Global Burden of Disease (GBD) and the use of disability-adjusted life years (DALYs) - a composite measure of premature deaths (years of life lost (YLLs)) and poor health (years lived with disability (YLDs)) - have revolutionized international health metrics (Table 1). In the previous GBD exercises,

${ }^{1}$ Faculty of Epidemiology and Population Health, London School of Hygiene and Tropical Medicine, London, UK; ${ }^{2}$ Institute for Health Metrics and Evaluation, Seattle, Washington; ${ }^{3}$ University of Queensland, School of Population Health, Herston, Australia; ${ }^{4}$ Department of International Health, Johns Hopkins Bloomberg School of Public Health, Baltimore, Maryland; ${ }^{5}$ Department of Newborn Medicine, Brigham and Women's Hospital, Boston, Massachusetts; ${ }^{6}$ Institute for Global Health, UCL Institute of Child Health, London, UK; ${ }^{7}$ Centre for Maternal Reproductive \& Child Health, London School of Hygiene and Tropical Medicine, London, UK; ${ }^{8}$ Saving Newborn Lives/Save the Children USA, Washington, DC. Correspondence: Joy E. Lawn (joy.lawn@lshtm.ac.uk) 


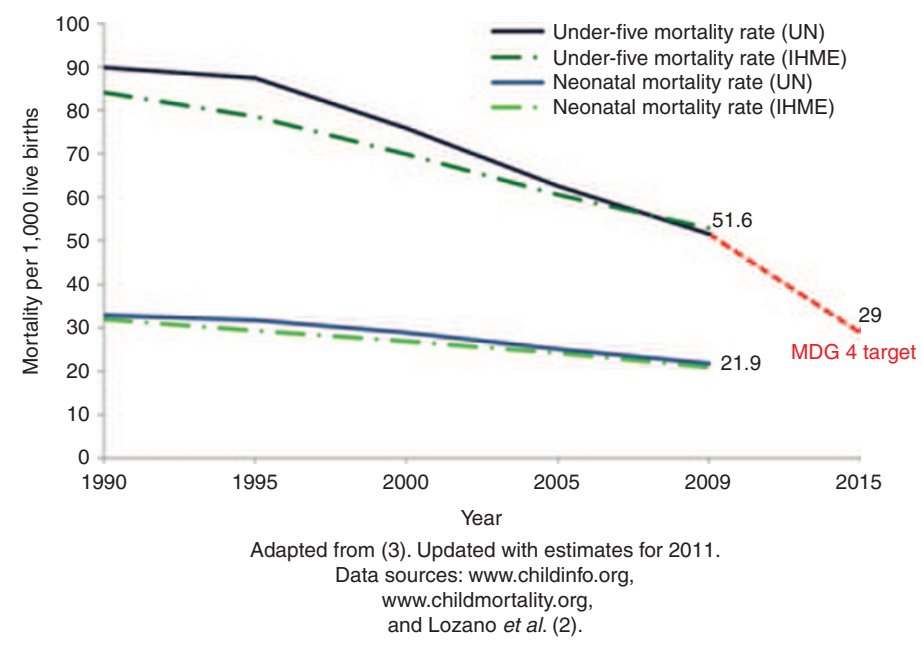

Figure 1. Progress toward Millennium Development Goal 4 for child survival showing progress for 193 countries based on estimates by the United Nations (UN) and by the Institute for Health Metrics and Evaluation (IHME).

"perinatal conditions" and congenital abnormalities together contributed at least $10 \%$ of the total burden, more than three times the DALYs attributed to HIV/AIDS $(12,13)$. However, limited description of the data inputs and estimation methods exists in the public domain. In December 2012, the latest GBD update (GBD2010) was published, presenting high-level methods and results for 291 conditions throughout the whole lifespan of a human, including DALYs at the global level (14-16).

The GBD expert team for neonatal conditions overlaps with the author group of this supplement. Here, we provide details for individual neonatal conditions in terms of data inputs, methods, and implications. In future, the GBD process aims to have continuous updates and in these articles, we outline where we have been able to increase or refine some of the data inputs since GBD2010 and to add some conditions that were not estimated in GBD2010, notably neonatal jaundice.

We have not included in this supplement the important burden of congenital abnormalities, which are estimated to contribute 2.6 million DALYs in 2010 (15). The inputs and methods for those will be summarized elsewhere. In addition, stillbirths are still uncounted in global burden estimates (17).

\section{OBJECTIVES AND STRUCTURE OF THE SUPPLEMENT}

The supplement presents the most comprehensive set yet compiled of regional and global estimates of the incidence of the most common neonatal morbidities and the associated burden of impairment and disability.

In this first article, we describe the step-by-step approach that we used to estimate the burden of neonatal conditions in 2010 . We also describe the methods used in GBD2010 to estimate trends over time and to generate YLDs and hence DALYs (used for preterm birth and intrapartum related conditions), in addition to presenting an overview of the relevant GBD2010 results. We then present a series of five articles quantifying the incidence/ prevalence and the long-term effects of some important causes of neonatal morbidity including preterm birth, retinopathy of prematurity, intrapartum-related neonatal encephalopathy, severe neonatal infections, and severe hyperbilirubinemia. Each article describes the systematic searches performed, the data inputs and modeling methods used, and presents the model outputs. The limitations of the currently available data are examined, recommendations are made for data improvement, and the programmatic implications of the results are discussed (Table 2). The major programmatic implications for health programs and proposed steps to improve measurement of the burden of neonatal morbidity to facilitate comparison within and between countries over time will be summarized elsewhere.

\section{METHODS}

\section{Literature Searches and Inputs for Estimation Parameters}

Systematic literature reviews were undertaken covering the main online literature databases, including Pubmed/Medline, Embase, CAB abstracts, Popline, Web of Science, Cumulative Index to Nursing and Allied Health Literature (CINAHL), Latin American and Caribbean Health Science (LILACS), and WHO Regional library databases (Eastern Mediterranean Regional Office (EMRO) Index Medicus, African Index Medicus, Pan American Health Organization (PAHO), Latin America and Caribbean Virtual Health Library, South East Asian Region (SEARO) Index Medicus, and Western Pacific Region (WPRO) Index Medicus). The aim of these searches was to identify data that could be used to estimate the parameters required as follows: (i) the incidence/prevalence of the neonatal condition of interest and any sex differences in incidence/prevalence. (ii) Case fatality risk for each condition during the neonatal period. (iii) Risk of impairment among babies surviving the neonatal period.

Details of search terms, condition-specific inclusion and exclusion criteria, and dates of last searches are provided in the condition-specific articles. Searches were last updated for each condition between December 2012 and January 2013, and hence, there are additional data included here that were not published at the time the expert group provided inputs to GBD2010 1 y previously.

\section{Overview of Three-Step Compartmental Model to Estimate Neonatal Survivors With Impairment}

A generic three-step compartmental model similar to that used in GBD2010 was applied to each condition (Figure 2). Specific differences between the inputs, methodology used, and results obtained here and those in GBD2010 are discussed in the relevant articles.

Step 1 involved estimation of the incidence/prevalence of the condition and hence the number of affected babies;

Step 2 involved estimation of the neonatal case fatality risk of the condition and hence the number of postneonatal survivors;

Step 3 involved estimating the risk of impairment and hence the number of these survivors who were impaired. 
Table 1. Terms and definitions used in burden of disease estimation

Neonatal mortality

YLL

YLD

GBD2010 disability weight

DALYs

Neurodevelopmental and sensory impairment outcomes

GBD2010

Compartmental model

Deaths in the first $28 \mathrm{~d}$ of life, per 1,000 live births

The number of years of life lost due to premature mortality, calculated as the number of deaths at each age multiplied by the standard life expectancy at that age (15).

The number of years lived in less than full health. It is calculated as the prevalence of the sequelae multiplied by the GBD2010 disability weight associated with the health state for that sequelae (15).

These were derived based on surveys of different populations in five countries (household surveys in Bangladesh, Indonesia, Peru, and Tanzania and telephone interviews in the USA) and an open access Web-based survey (23). These surveys used paired comparison questions in which participants were asked to consider two hypothetical individuals with different health states and to state which person they considered healthier.

This is an absolute measure of health loss, which counts how many years of healthy life are lost due to death or nonfatal illness or impairment. It is calculated as the sum of YLLs and YLDs. GBD2010 differed from previous GBD studies in that no age weighting or discounting was used (less weight given to younger and older ages); prevalent YLDs rather than incident YLDs were calculated; and adjustment was made for comorbidity (19).

A standard approach was used to assess neurodevelopmental and sensory impairment outcomes from the available study data. Neurodevelopmental impairment was classified as mild (mild cognitive and/or mild motor impairment) and moderate/ severe (either cognitive and/or motor impairment of at least moderate severity). Details of the impairment outcome definitions used across all articles in this supplement are provided in Table 5.

This is the most recent edition of the Global Burden of Disease project coordinated by the IHME in Seattle but involving many experts around the world. For details, see http://www.healthmetricsandevaluation.org/.

This refers to a basic epidemiological model where the population is divided into compartments and with assumptions about the nature and time rate of transfer from one compartment to another. In this supplement, we use a three-step compartmental model as follows: Step 1: incidence or prevalence of the condition. Step 2: risk of death from the condition, leading to an estimate of survivors. Step 3: risk of impairment among survivors, leading to numbers of impaired or unimpaired survivors. Diseases that recur or may confer immunity have more complex compartmental linkages, but for neonatal conditions, these are usually a single episode, or of short duration, and the impairment effects are typically lifelong (Figure 2).

The definitions and ICD codes for each neonatal condition are specified in the condition-specific articles.

DALYS, disability-adjusted life years; GBD, Global Burden of Disease; ICD, International Classification of Diseases; YLD, years lived with disability; YLL, years of life lost.

Table 2. Estimates of neonatal morbidities and long-term impairment included in the articles in this supplement

Preterm birth (27)

Prevalence of preterm birth by gestational age

Gestational age-specific neonatal mortality

Mild and moderate/severe long-term impairment following preterm birth by gestational age

Retinopathy of prematurity and long-term visual impairment associated with preterm birth (33)

Incidence of retinopathy of prematurity by gestational age

Number requiring treatment

Long-term visual impairment after retinopathy of prematurity

Intrapartum-related conditions (28)

Incidence of intrapartum-related neonatal encephalopathy

Intrapartum-related neonatal encephalopathy case fatality rate

Mild and moderate/severe long-term impairment following

intrapartum-related neonatal encephalopathy

Neonatal severe bacterial infections (29)

Incidence of possible severe bacterial infection

Neonatal infection case fatality rate by infection syndrome

Mild and moderate/severe long-term impairment following neonatal meningitis and tetanus

Neonatal hyperbilirubinemia (31)

Incidence of severe neonatal hyperbilirubinemia and kernicterus

Kernicterus case fatality rate

Mild and moderate/severe long-term impairment following neonatal encephalopathy
The calculation of YLDs (Figure 2) was only undertaken for conditions in GBD2010 (preterm- and intrapartum-related conditions).

The steps above were applied in sequence for all live births in each country in 2010 using the number of live births by country from the UN population division (18). Unpublished data from UNPOP's WPP2010 series were used to estimate the number of live births by sex so that sex-specific estimates could be made. Country-level results were then summed to produce regional estimates. Results are presented by GBD superregional grouping, which condenses the $21 \mathrm{GBD}$ regions into 7 (Figure 3; see Supplementary Information online) (19).

Data abstracted from the literature searches were used as inputs to estimate the parameters required for each condition, undertaking meta-analyses where appropriate. Time trends from 1990 to 2010 were calculated for conditions when sufficient data were available. However, owing to the lack of comparable time series data, robust trend estimates were not possible for many conditions.

We quantified the uncertainty surrounding these estimates by taking 1,000 random draws of the input parameters at each step, assuming a normal distribution with mean equal to the point estimate of the parameter and SD equal to the estimated SE of the parameter. We summed the data at the worldwide or regional level for each draw and present the 2.5th and 97.5th percentiles of the resulting distributions as the uncertainty range.

We did not estimate YLDs using the compartmental model and hence did not estimate DALYs. All DALYs presented in this supplement are those calculated for GBD2010, and we note where the data inputs differ from those used for GBD2010.

\section{Pooling of Data by Country Context Groupings}

Data were not available to estimate every parameter individually for each country, or for some conditions (or impairment outcomes), data were sparse even at the regional level. Hence, we sought to group countries that are similar in their access to and quality of care because these are closely linked to outcomes, including case fatality rate, risk of impairment, and excess postneonatal mortality risk. We also sought to apply a common approach across all the estimation exercises in this supplement. Recent work has highlighted the very different contexts, 


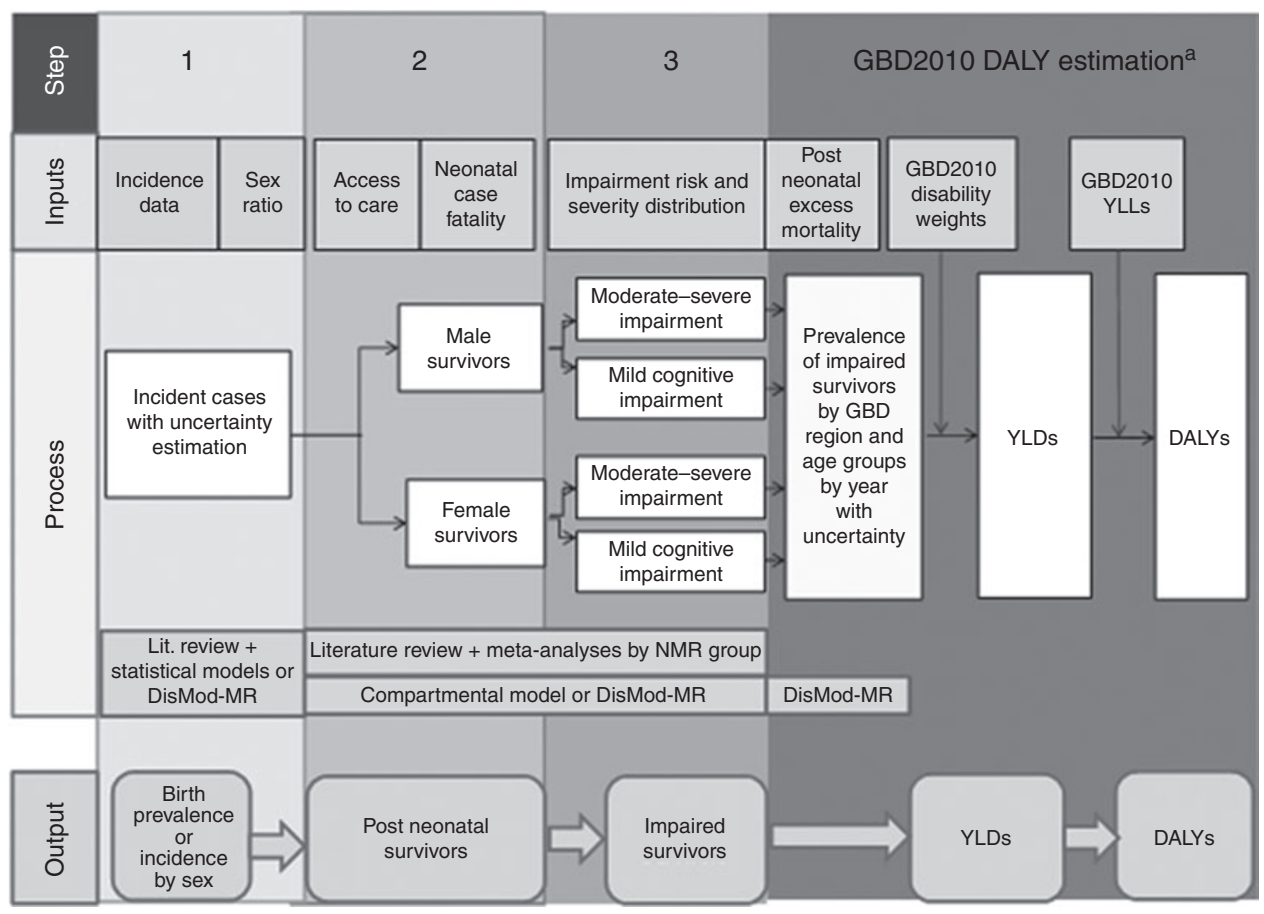

Figure 2. Overview of parameters required and methods for estimation of the global burden of neonatal conditions. ${ }^{\text {aThe }}$ analyses for years lived with disability and disability-adjusted life years were undertaken in the Global Burden of Disease study for preterm birth and intrapartum-related conditions and will be detailed in the articles in the supplement.

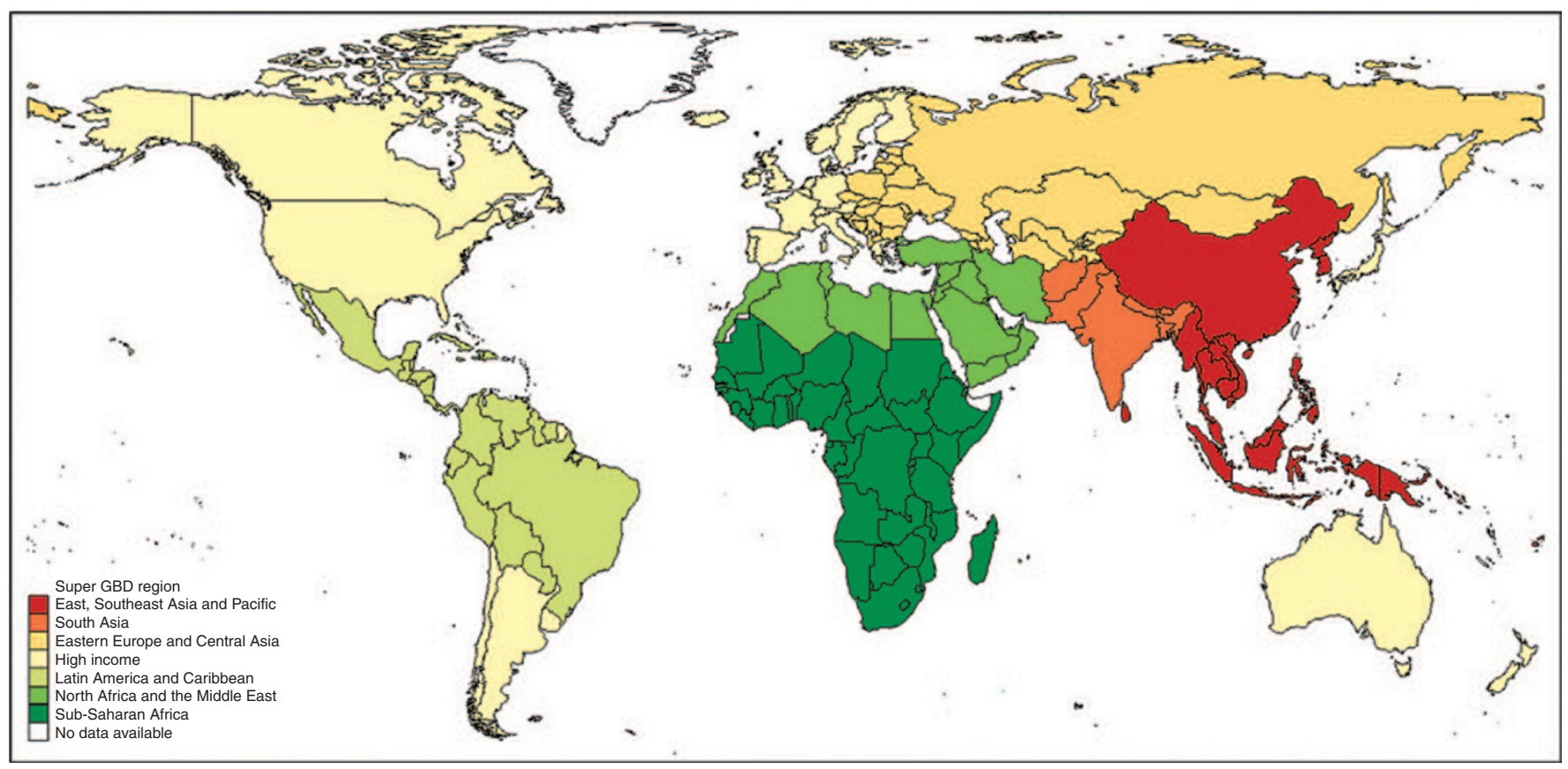

Figure 3. Regional groups used in the Global Burden of Disease (GBD) 2010 estimation. Regional groupings based on super-GBD regions, which condenses the $21 \mathrm{GBD}$ regions into 7 (19).

health system capacities, and funding available in different countries or even in differing subnational contexts in large countries such as India or Nigeria. There is a correlation between these health system factors and neonatal mortality rate (3). We therefore grouped countries into three neonatal mortality rate (NMR) bands as follows: group 1 (NMR < 5), group 2 (NMR 5 to $<15)$, and group $3(\mathrm{NMR} \geq 15)$. We used NMR estimates from the UN Interagency Group on Child Mortality Estimation (IGME) (1). For South Africa, we used locally derived national estimates, with improved methodology to account for the effects of HIV on mortality over this time period (20). Table 3 shows that although almost $90 \%$ of neonatal deaths occur in countries with NMR $\geq 15$, these highest-burden countries have a median of only 2 physicians per 10,000 population and US $\$ 23$ spending on capita per year, compared with countries with $\mathrm{NMR}<5$, which have a median of 29 physicians per 10,000 population, health spending of US\$1452 per capita, and virtually universal coverage of neonatal intensive care.

We applied this NMR grouping and assigned each study to one of these NMR levels based on the national estimate of the NMR in the 


\section{Articles | Blencowe et al.}

Table 3. Countries $(N=184)$ according to three levels of neonatal mortality rate showing the variation in context and health system capacity around the year 2010

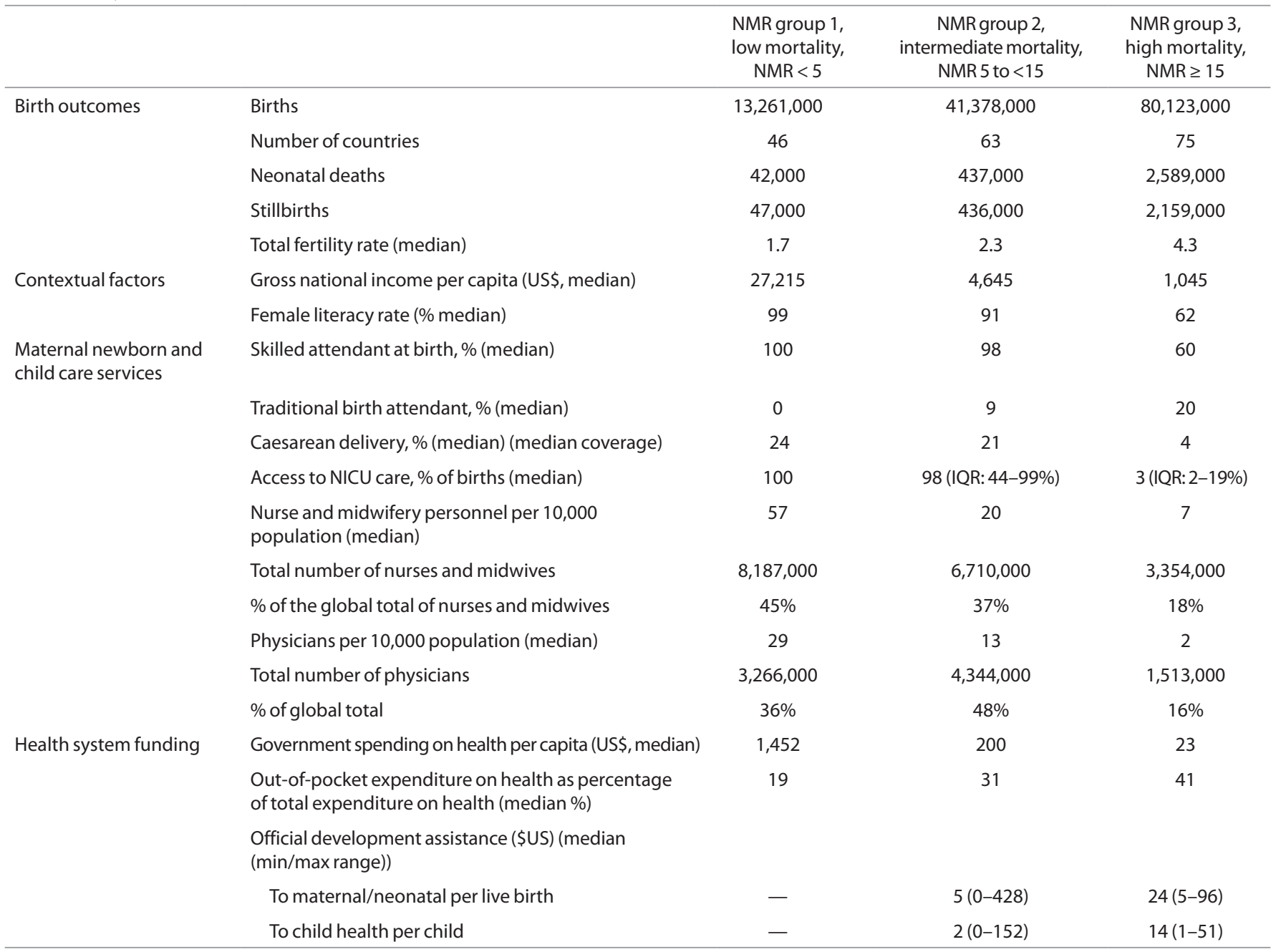

Table adapted from Lawn et al. (3) Data sources: State of the World's Children 2011 (40), UN Millennium Developmental Goal Report 2011 (41), WHO Global Atlas (42), WHO National Health Accounts (43), Pitt et al. (44). Note: Country groupings by level of NMR adapted from The Lancet Neonatal Series 2005 (45) and estimates exclude nine countries with annual births $<10,000$.

year of the study. We pooled data from all studies in the same mortality group to obtain parameter estimates using meta-analysis and applied the resulting parameter estimates to all countries in that mortality group. This approach was used for GBD2010 and the compartmental models for all conditions. However, it should be noted that the NMRs and the access to and quality of care may vary substantially within individual countries. In countries with large variations between different areas, subnational analysis would be preferable but this was not possible due to data limitations.

\section{Neonatal Care Coverage}

Neonatal outcomes are highly dependent on both gestational age at birth and extrinsic influences, particularly the quality of care received. During the past few decades, improved availability and quality of neonatal care in high-income countries has led to reduced mortality and risk of impairment in surviving babies born before $32 \mathrm{wk}$ of gestation. However, in many settings, quality of care remains low, and this may increase the risk of iatrogenic damage, resulting in higher risk of impairment in survivors.

Most of the available literature considers outcomes among babies who received a particular type of care, in a particular setting, and at a particular time. When using these data to estimate outcomes for babies born in 2010, results are sensitive to assumptions about the likely proportions of babies receiving different levels of care. For estimates relating to preterm birth, retinopathy of prematurity, and jaundice estimates, we considered the following three scenarios of neonatal care:

1. Full availability of all levels of neonatal care (including NICU): high-intensity care including as a minimum high-tech monitoring, ventilation, and high nurse-to-patient ratio. In many settings, this will also include use of surfactant therapy.

2. Some availability of specialized neonatal care (including Neonatal Special Care): facility-based care usually in a newborn ward, with dedicated nursing staff and some availability of supportive care, e.g., external heat sources, feeding support (cup or nasogastric tube), and antibiotics \pm Kangaroo Mother Care, in settings with no availability of referral to NICU care. These units may have access to some specific low-tech treatments such as oxygen and phototherapy.

3. No availability of specialized neonatal care (basic/limited care only): this could be at home or in a facility with no access to Neonatal Special Care or NICU care. This category can vary from effective simple care at birth with warmth, cleanliness, and breastfeeding support, to some settings where the baby is delivered onto a dirty floor, not dried or assessed for breathing, and not fed for several hours.

Even in high-income countries, there are very few data on coverage of neonatal care, and data are lacking from other regions. 
For consistency with previous work on coverage of care around the time of birth, we estimated coverage of neonatal care based on facility birth coverage as included in the Lives Saved Tool. Given the lack of data for the coverage of Neonatal Special Care, we assumed this to be similar to the coverage of Comprehensive Emergency Obstetric Care, which does have national estimates for many countries (21). This is likely to overestimate true coverage because much less investment has been made in the necessary newborn care competencies although neonatal resuscitation has received increased attention in very recent years. For NICU coverage, we undertook literature- and Web-based searches to identify low- and middle-income countries with data on the number of neonatal intensive care beds and further developed a coverage indicator based on coverage of facility birth, assuming a requirement of approximately one NICU cot per 1,000 live births (see Supplementary Information online) (22).

\section{Mortality Estimation}

Although the purpose of this supplement is to estimate impairment among survivors of neonatal conditions, and not to generate new estimates of neonatal mortality, the three-step compartmental model used required us to estimate case fatality risks and deaths to estimate the number of postneonatal survivors. These estimated numbers of deaths, based on case fatality risks estimated from relatively few data inputs, are less robust than other cause-of-death estimates using other methods $(2,10)$ but are presented to provide a consistency check on the three-step modeling process.

Mortality estimates are required for the YLL component of DALYs and for consistency checks with numbers of deaths generated by the case fatality risk approach in the three-step model. There are also two estimates of the numbers of neonatal deaths in 2010; one by the United Nations (3.1 million) (1) and the second by the IHME (2.9 million) and used in GBD2010 $(2,14)$. There are also two sets of estimates for causes of deaths within the neonatal period for the year 2010, with time trends, one recently published by the IHME as part of GBD2010 (Table 4) (14), and one published earlier, with child and neonatal cause of death and time trends, in addition to a WHOfacilitated country clearance process (10). Both have similar inputs as vital registration and Verbal Autopsy data, and although the GBD modeling methods (Table 4) are different from the UN estimation methods, in the main, the neonatal cause-of-death estimates in terms of proportions are similar. We will refer to both sets of estimates.

\section{Calculation of DALYs in GBD2010}

GBD2010 calculated DALYs for both 1990 and 2010 as the sum of YLLs and YLDs. YLDs were calculated by combining estimates of the prevalence of the condition at all ages, generated by a Bayesian meta-regression tool, DisMod-MR, with a disability weight assigned by GBD2010 (Tables 5 and 6) (16,23). In DisMod-MR, all those with moderate to severe outcomes were modeled together. This combines a range of health state combinations, each with their own disability weight. To avoid combined disability from multiple conditions in one person exceeding a disability weight of one, a multiplicative function of disability weights (DWs) for health states that occur in the same person is assumed: DW combined $=1-(1-\mathrm{DW} 1) \times(1-\mathrm{DW} 2) \ldots \times$ $(1-\mathrm{DWn})$. To estimate the distribution of combinations of different health states, we took up the distribution of the impairment outcomes and combinations of outcomes from one study each for preterm birth complications (24) and intrapartum-related neonatal encephalopathy (25). These small studies were the only sources of information on the distribution of sequelae and their severity. We propagated these distributions with uncertainty and the relevant disability weight for each health state by undertaking 1,000 draws from these to achieve a combined weight. Mild outcomes were modeled separately assuming that $50 \%$ of those with mild impairment had isolated mild motor problems and that $50 \%$ had mild motor and mild cognitive impairment. Isolated cognitive impairment was not considered in GBD2010 for neonatal conditions but will be included in the future continuous GBD updates.

YLLs for neonatal conditions in GBD2010 were from IHME estimates using life tables and the Cause of Death Ensemble model (Table 4) (14). One important change in GBD methodology related to the neonatal period is the removal of both (i) discounting, which had the effects of reducing the "value" of a neonatal death compared with the death of an adult and (ii) age weighting, which gave higher weight for hypothetical adult years lost and lower weight for YLL in children and the older adult (26).

\section{GBD2010-Specific Methods and Differences From the Estimates in This Supplement}

The main differences between GBD2010 and the estimates in this supplement are summarized in Table 7. For preterm birth- and intrapartum-related conditions, the experts in this supplement provided input parameters to DisMod-MR. Since submission to GBD in early 2012 , the input data for all these conditions have been further updated, and

Table 4. Estimation of YLL in GBD2010

\begin{abstract}
Data inputs
In GBD2010, the number of cause-specific neonatal deaths was estimated based on 3,363 vital registration, 225 verbal autopsy, and 25 surveillance data sources. Estimated mortality from all neonatal conditions were combined and estimates generated for four specific causes: preterm birth complications, intrapartum-related neonatal deaths, sepsis and other infectious conditions of the newborn, and other conditions arising in the neonatal period ensuring that these added up to the total mortality for neonatal conditions.

Modeling

Total deaths attributable to neonatal causes (i.e., not all neonatal deaths) were modeled using CODEm estimating deaths for males and females separately (16). CODEm is based on five general principles: identifying all available data, maximizing the comparability and quality of the data set, developing a diverse set of plausible models, assessing the predictive validity of each plausible individual model and of ensemble models, and choosing the model or ensemble model with the best performance in out-of-sample predictive analysis. Possible models are identified based on statistical methods (mixed effects linear models or spatial-temporal Gaussian process regression applied to the log of death rates or the logit of cause fractions) and combining these with a range of plausible combinations of covariates. Each model is tested on how well it predicts $30 \%$ of the data that are deliberately left out of a model, using statistical out-of-sample predictive validity measures. The following covariates were considered: health system access (a composite covariate measuring various aspects of health service provision), smoking prevalence among women of reproductive age, indoor air pollution, anti-retroviral-adjusted HIV prevalence, malnutrition, skilled attendance at birth, in-facility delivery, education among women of reproductive age, the log of the total fertility rate, and the natural log of lagged-distributed income per capita. In total, 910 total models were tested based on various combinations of these covariates. Ensemble models (averaging results from the best-performing single models) were created, tested, and compared with the best-performing individual models. The ensemble models performed better on out-of-sample predictive performance. Each of the four subcauses were modeled again separately, using CODEm, and then these subcause estimates were scaled to the total number of neonatal deaths estimated in the first step, taking into account the levels of uncertainty associated with each estimate.
\end{abstract}

Full details are available in the studies of Foreman et al. (46) and Lozano et al. (14).

GBD2010 mortality estimates are presented as part of DALYs in this article and in the two conditions in this supplement with GBD2010 DALYs detailed (preterm and intrapartumrelated conditions). In the comparisons with the three-step compartmental model mortality outputs, both UN and GBD neonatal mortality estimates are discussed.

CODEm, cause of death ensemble model; DALYs, disability-adjusted life years; GBD, Global Burden of Disease; ROP, retinopathy of prematurity; YLD, years lived with disability; YLL, years of life lost. 


\section{Articles | Blencowe et al.}

Table 5. Classification of disability applied in GBD2010 related to neonatal conditions in terms of domain affected, severity, and consequences on daily living

\begin{tabular}{|c|c|c|c|c|}
\hline & Domain & $\begin{array}{l}\text { Assessment definition used in this } \\
\text { supplement }\end{array}$ & $\begin{array}{l}\text { Lay description used in GBD2010 in terms of activities } \\
\text { of daily living ( } 21 \text { ) }\end{array}$ & $\begin{array}{l}\text { GBD2010 disability } \\
\text { weight ( } 21)(95 \% \\
\text { uncertainty range) }\end{array}$ \\
\hline \multirow[t]{5}{*}{$\begin{array}{l}\text { Neuro- } \\
\text { developmental }\end{array}$} & $\begin{array}{l}\text { Mild motor } \\
\text { impairment }\end{array}$ & $\begin{array}{l}\text { Difficulty in everyday motor } \\
\text { activities but able to move around } \\
\text { without help }\end{array}$ & $\begin{array}{l}\text { Has some difficulty in moving around but is able to } \\
\text { walk without help. }\end{array}$ & $0.012(0.005-0.022)$ \\
\hline & $\begin{array}{l}\text { Mild motor and } \\
\text { intellectual } \\
\text { impairment }\end{array}$ & $\begin{array}{l}\text { Cognitive Z-score }-1 \text { to }-2 \text { SD for } \\
\text { test (DQ 70-84) and mild motor } \\
\text { impairment }\end{array}$ & $\begin{array}{l}\text { Has some difficulty in moving around, and is slow in } \\
\text { learning at school. The person can walk without help, } \\
\text { work at simple supervised jobs and live independently } \\
\text { but often needs help to raise children. }\end{array}$ & $0.054(0.033-0.084)$ \\
\hline & $\begin{array}{l}\text { Moderate motor } \\
\text { impairment }\end{array}$ & $\begin{array}{l}\text { Difficulty in holding implements, } \\
\text { dressing, and sitting upright. Able } \\
\text { to move around with help }\end{array}$ & $\begin{array}{l}\text { Has some difficulty in moving around and has difficulty } \\
\text { in lifting and holding objects, dressing, and sitting } \\
\text { upright but is able to walk without help. }\end{array}$ & $0.076(0.05-0.109)$ \\
\hline & $\begin{array}{l}\text { Moderate motor } \\
\text { and intellectual } \\
\text { impairment }\end{array}$ & $\begin{array}{l}\text { Cognitive Z-score }-2 \text { to }-3 \text { SD for } \\
\text { test (DQ 55-69) and moderate } \\
\text { motor impairment }\end{array}$ & $\begin{array}{l}\text { Has some difficulty in moving around, holding objects, } \\
\text { dressing, and sitting upright and is slow in learning to } \\
\text { speak and do simple tasks. The person can walk without } \\
\text { help but requires a lot of help with daily activities. }\end{array}$ & $0.221(0.141-0.314)$ \\
\hline & $\begin{array}{l}\text { Severe motor } \\
\text { and intellectual } \\
\text { impairment }\end{array}$ & $\begin{array}{l}\text { Cognitive } Z \text {-score } \leq-3 \text { SD for } \\
\text { test }(D Q<55) \text { and severe motor } \\
\text { impairment }\end{array}$ & $\begin{array}{l}\text { Cannot move around without help and cannot lift or } \\
\text { hold objects, get dressed, or sit upright. The person } \\
\text { also has low intelligence, speaks few words, and needs } \\
\text { a lot of help with all basic daily activities. }\end{array}$ & $0.425(0.286-0.587)$ \\
\hline \multirow[t]{2}{*}{ Seizures } & \multirow{2}{*}{$\begin{array}{l}\text { Severe epilepsy (>1 } \\
\text { seizure per month); } \\
\text { untreated epilepsy } \\
\text { ( }>1 \text { seizure per } \\
\text { month); treated } \\
\text { epilepsy with recent } \\
\text { seizures ( }>1 \text { per year } \\
\text { and }<1 \text { per month); } \\
\text { treated epilepsy } \\
\text { without recent } \\
\text { seizures ( }<1 \text { per } \\
\text { year) }\end{array}$} & $\begin{array}{l}\text { More than one nonfebrile } \\
\text { seizure per month }\end{array}$ & $\begin{array}{l}\text { Has sudden, prolonged seizures once a week, with } \\
\text { violent muscle contractions and stiffness, loss of } \\
\text { consciousness, and loss of urine or stool control. } \\
\text { Between seizures, the person has drowsiness, memory } \\
\text { loss, difficulty concentrating, and anxiety. }\end{array}$ & $0.657(0.464-0.827)$ \\
\hline & & - & $\begin{array}{l}\text { Untreated has sudden seizures twice a month, with } \\
\text { violent muscle contractions and stiffness, loss of } \\
\text { consciousness, and loss of urine or stool control. Between } \\
\text { seizures, the person has anxiety about future episodes. }\end{array}$ & $0.42(0.279-0.572)$ \\
\hline \multirow[t]{4}{*}{ Vision } & $\begin{array}{l}\text { Mild visual } \\
\text { impairment }\end{array}$ & $\begin{array}{l}\text { Visual acuity in the best eye } \\
<6 / 12 \text { but better or equal to } 6 / 18 \text {, } \\
\text { or corresponding visual field loss }\end{array}$ & $\begin{array}{l}\text { Has some difficulty with distance vision, for example, } \\
\text { reading signs, but no other problems with eyesight. }\end{array}$ & $0.004(0.001-0.1)$ \\
\hline & $\begin{array}{l}\text { Moderate visual } \\
\text { impairment }\end{array}$ & $\begin{array}{l}\text { Visual acuity in the best eye }<6 / 18 \\
\text { but better or equal to } 6 / 60 \text {, or } \\
\text { corresponding visual field loss }\end{array}$ & $\begin{array}{l}\text { Has vision problems that make it difficult to recognize } \\
\text { faces or objects across a room. }\end{array}$ & $0.033(0.02-0.52)$ \\
\hline & $\begin{array}{l}\text { Severe visual } \\
\text { impairment }\end{array}$ & $\begin{array}{l}\text { Visual acuity in the best eye } \\
<6 / 60 \text { but }>3 / 60 \text {, or visual field } \\
\text { loss }\end{array}$ & $\begin{array}{l}\text { Has severe vision loss, which causes difficulty in daily } \\
\text { activities, some emotional impact (for example, worry), and } \\
\text { some difficulty going outside the home without assistance. }\end{array}$ & $0.191(0.129-0.272)$ \\
\hline & Blindness & $\begin{array}{l}\text { Visual acuity in the best eye } \\
<3 / 60 \text {, or corresponding visual } \\
\text { field loss }\end{array}$ & $\begin{array}{l}\text { Is completely blind, which causes great difficulty in some } \\
\text { daily activities, has worry and anxiety and faces great } \\
\text { difficulty going outside the home without assistance. }\end{array}$ & $0.195(0.132-0.272)$ \\
\hline \multirow[t]{3}{*}{ Hearing } & $\begin{array}{l}\text { Mild hearing } \\
\text { impairment }\end{array}$ & $\begin{array}{l}\text { Audiometric hearing threshold } \\
\text { level of } 26-30 \text { decibel }(\mathrm{dBHL})\end{array}$ & $\begin{array}{l}\text { Has difficulty following a conversation in a noisy } \\
\text { environment but no other hearing problems. }\end{array}$ & $0.005(0.002-0.012)$ \\
\hline & $\begin{array}{l}\text { Moderate hearing } \\
\text { impairment }\end{array}$ & $\begin{array}{l}\text { Audiometric hearing threshold } \\
\text { level of } 35-64.9 \mathrm{dBHL}\end{array}$ & $\begin{array}{l}\text { Has difficulty hearing a normal voice and great } \\
\text { difficulty following a conversation in a noisy } \\
\text { environment. }\end{array}$ & $0.023(0.013-0.038)$ \\
\hline & $\begin{array}{l}\text { Severe hearing } \\
\text { impairment or } \\
\text { deafness }\end{array}$ & $\begin{array}{l}\text { Audiometric hearing threshold } \\
\text { level of } 65 \mathrm{dBHL} \text { or greater }\end{array}$ & $\begin{array}{l}\text { Has great difficulty hearing in any situation or in using } \\
\text { the phone. }\end{array}$ & $0.032(0.018-0.051)$ \\
\hline
\end{tabular}


Table 6. Estimation of years lived with disability (YLD) in Global Burden of Disease 2010 with Bayesian modeling through DisMod-MR

Data inputs

For a given condition, data are entered regarding the following epidemiological parameters: prevalence, incidence, mortality risk, remission (i.e., cure) rate, and where relevant, the duration of the condition. GBD2010 uses the data sets developed by the IHME for births by country and sex from 1990 to 2010 and forward projections, along with multiple covariate time series.

Modeling

DisMod-MR is a complex Bayesian meta-regression tool developed for GBD2010 to combine all available epidemiological data for the parameters noted above and estimate the prevalence of a given condition by sex and year. Estimates use a generalized negative binomial model for all the epidemiological data, with various types of fixed effects for age, study quality characteristics (such as case definition, representativeness of study), country characteristics (such as gross domestic product or level of health service access), and random effects for countries, regions, and superregions (16). It aims to estimate all sources of uncertainty as much as possible, including sampling and nonsampling errors. In previous iterations of GBD, earlier versions of DisMod concentrated on consistency checking between these parameters. Previous DisMod versions required the analyst to make a choice of the most appropriate data points by age and sex for each parameter and for each population of interest. In GBD2010, the aim was to minimize such choices by analysts. The software needs to run on a large cluster of servers as it is computationally very intensive. A version that can run on local computing resources for use by countries wanting to update their GBD results is being developed. Full details in Vos et al. (16).

GBD2010 YLD estimates are presented as part of DALYs in this article and in the two conditions in this supplement with GBD2010 DALYs detailed (preterm and intrapartum-related conditions).

DALYs, disability-adjusted life years; GBD, Global Burden of Disease; IHME, Institute of Health Metrics and Evaluation.

in the following articles in this supplement, we describe where the main differences are $(27,28)$.

For neonatal infections, GBD2010 used different data inputs and a different approach from the compartmental model presented in this supplement (29). For neonatal meningitis, incidence from facilitybased studies (including very preterm babies in NICUs) was used to estimate population incidence and impairment risks from older infants and children applied (30). For neonatal sepsis, the incidence was back calculated from the GBD2010 estimated number of deaths using a pooled estimate of case fatality rate for neonatal sepsis. Only YLDs from the acute illness were included for neonatal sepsis, assuming the duration of the acute illness to be $1 \mathrm{wk}$. For neonatal hyperbilirubinemia (jaundice), it was included in the category "other neonatal conditions" and not estimated separately. YLDs for "other neonatal conditions," which includes all other ICD10 codes in Chapter 9 of ICD not captured in the main categories of preterm birth, intrapartum-related conditions, and neonatal infections, were estimated by taking the ratio YLD/YLL for intrapartum-related conditions and preterm births and applying this ratio to the YLL for the "other neonatal conditions" category. As detailed above this is not the same as all conditions in the neonatal period because some important conditions are not present in Chapter 9 of ICD10 on perinatal conditions, such as neonatal tetanus, congenital syphilis, and other perinatal sequelae of sexually transmitted diseases. In this supplement, neonatal jaundice, which was subsumed in the GBD2010 "other neonatal" category, is estimated separately (31).

\section{RESULTS}

GBD2010 estimates a total of 2.5 billion DALYs worldwide in 2010. The first $28 \mathrm{~d}$ of life are important contributors to this burden, with nearly one-tenth (245 (uncertainty range: 224-265) million) of all DALYs estimated to arise from events during the first $28 \mathrm{~d}$ of life (15). The term "neonatal conditions" includes only conditions in the newborn included in Chapter 9 of ICD10 (International Classification of Diseases) (32), including preterm birth, neonatal encephalopathy, and neonatal sepsis, which account for an estimated 202 million DALYs, 8.1\% (uncertainty range: $7.3-9.0 \%$ ) of the worldwide total (Figure 4). Hence this grouping in GBD of "neonatal conditions" does not include several important specific infections in the neonatal period, such as pneumonia, meningitis, tetanus, or congenital syphilis, which are grouped under infectious diseases. Congenital conditions are also not included, even if the death occurs in the neonatal period.
Summary results from GBD2010 for neonatal conditions in 2010 are presented in Table 7, along with a summary of any methodological differences between the GBD2010 DisMod-MR input parameters (or process) and the 2010 three-step compartmental model used in this supplement. More details are given in the other articles in this supplement (27-29,31,33).

GBD provides an assessment of change in the burden of 291 conditions over time, and one notable shift is the reduced contribution of deaths to the DALY total and the increased contribution of disability. Two exceptions to this shift are (i) the continent of Africa, which still has high premature mortality and (ii) neonatal conditions. In contrast with many other conditions, deaths (YLLs) are responsible for the majority of DALYs attributable to neonatal conditions across all regions. GBD2010 estimated that in 2010, 2.84 million deaths occurred in the neonatal period and that YLLs contribute $96 \%$ of preterm, $88 \%$ of intrapartum-related conditions, and nearly $100 \%$ of neonatal sepsis DALYs (Table 7). However, this overall picture, dominated by large numbers of deaths in low-income regions, masks the fact that in high- and middle-income regions with relatively low mortality levels and increased survival of the sickest newborns, YLDs associated with long-term impairment contribute a higher proportion of the overall DALYs. For example, YLDs comprise $17 \%$ of DALYs in high-income countries (34).

The results of GBD2010 suggest that the relative contribution of these neonatal conditions to the global burden of DALYs has reduced by $26 \%$, from $10.9 \%$ of worldwide total (274 million DALYs) in 1990 to $8.1 \%$ (202 million) in 2010. This reduction in the number of these DALYs is largely accounted for by the reduction in the number of deaths (YLLs) from these conditions. For conditions for which YLDs are calculated, the total YLDs are estimated to have increased during the same period (preterm birth complications by $29.7 \%$ and intrapartum-related conditions by $9 \%$ ) due to the increase in the number of live births. However, there is substantial uncertainty around these trend estimates, and caution should be applied when interpreting these results (see Supplementary Information online). 


\section{Articles | Blencowe et al.}

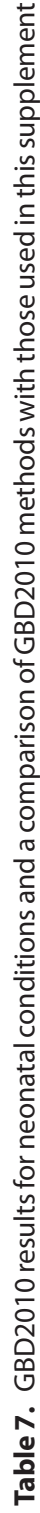

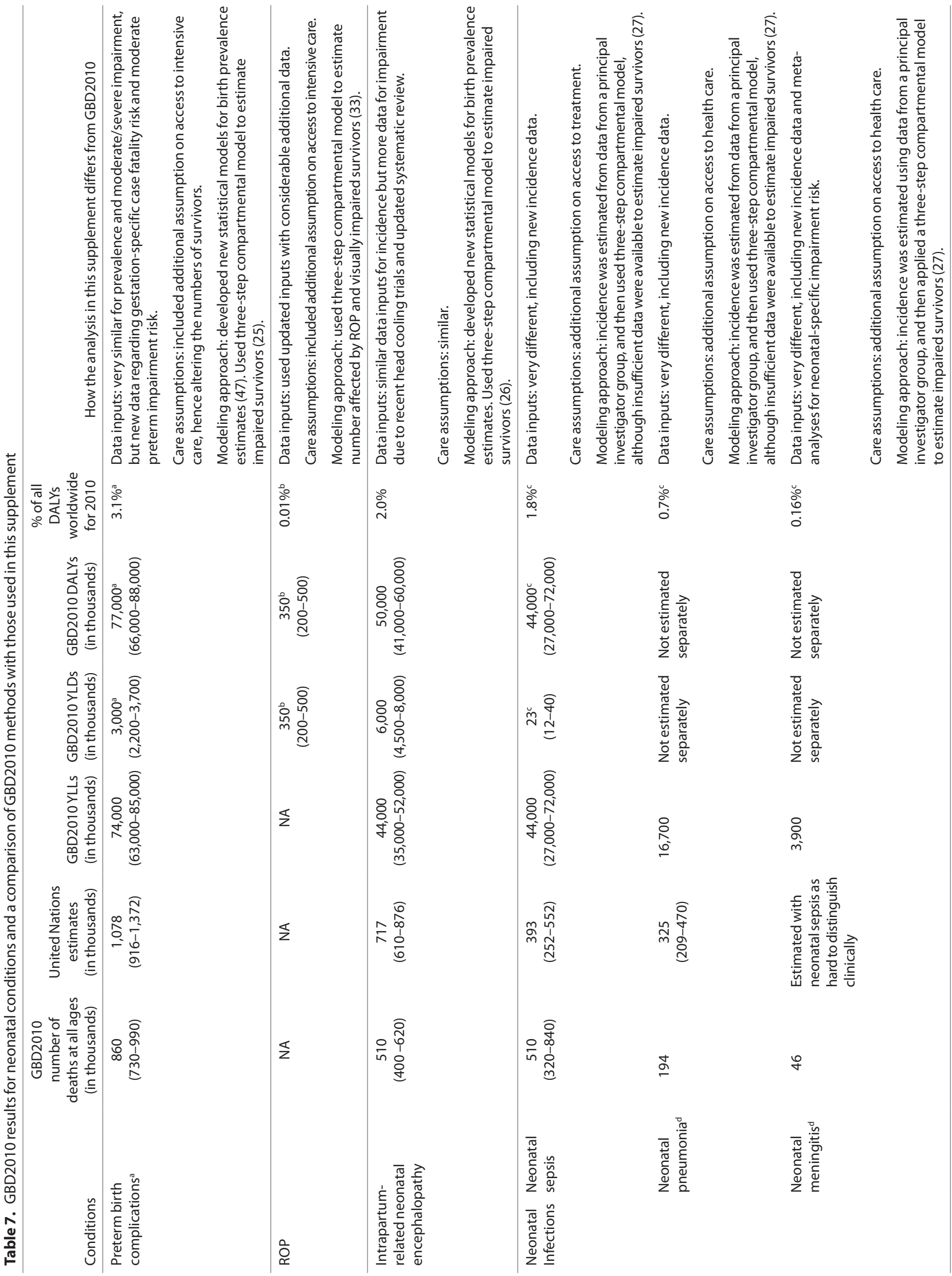




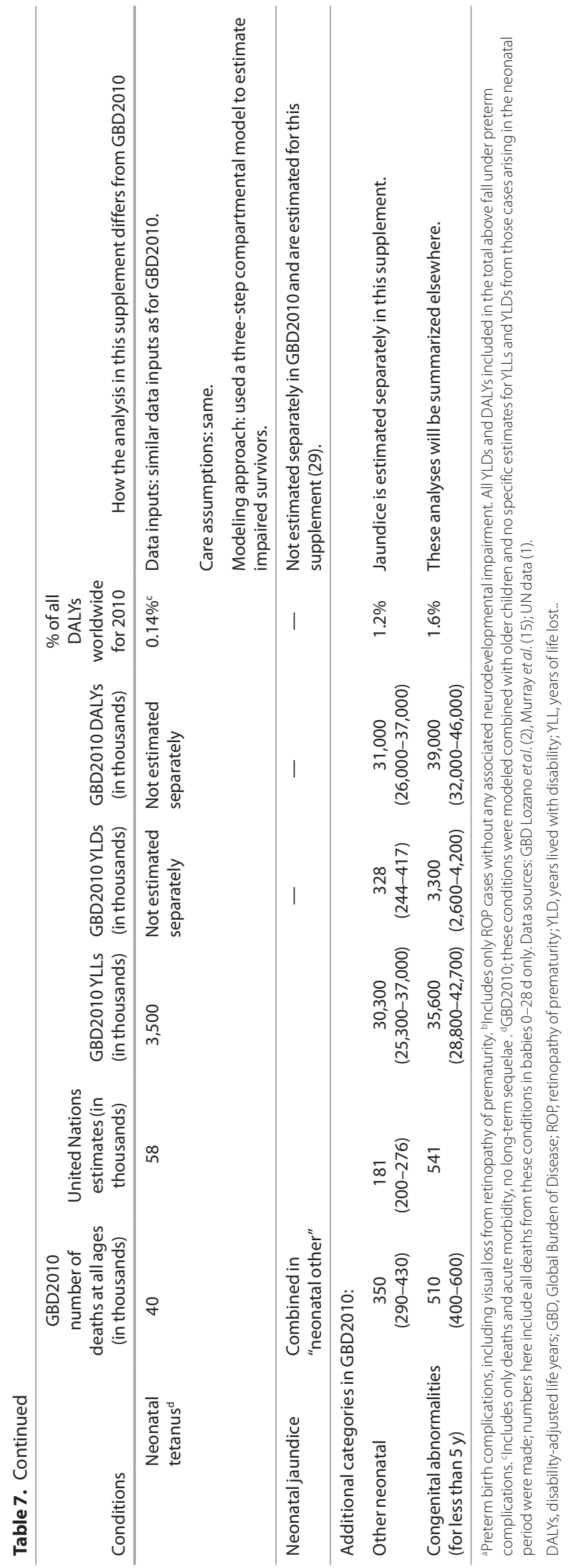

\section{DISCUSSION}

The recent GBD2010 project has highlighted the increasing importance over time of the burden of YLDs (15) and the rise of noncommunicable diseases and has drawn attention to mental health issues and disabilities, such as those from musculoskeletal conditions, while in general, infections and maternal conditions have reduced in magnitude of burden. Neonatal conditions, however, still constitute an important portion of the overall GBD in GBD2010, accounting for 8.1\% of global DALYs in 2010, which is about the same share as in 1990. Their importance is primarily in terms of an excess of death very early in life and consequently high numbers of YLL. However, in high- and middle-income regions with improving survival rates, YLDs have increased in importance. It should be noted that GBD2010 starts from live births. The 2.6 million babies who die as stillbirths in the last trimester of pregnancy (35), including the 1.2 million who die as intrapartum stillbirths (17), some just minutes before birth, are not yet counted within GBD2010 (36), or indeed in other efforts to track global health (37).

These estimates underline the fact that even without counting 2.6 million stillbirths, the burden due to unhealthy birth outcomes and newborn complications is important in every country and every region of the world. Greater focus on reducing the incidence of these conditions and improving the care of those affected to reduce both early mortality and impaired survival is required. Improved coverage and quality of neonatal care services are required across the continuum from the community, through primary- and secondary-level care to neonatal intensive care. In addition, greater accountability for counting birth outcomes is critical.

The estimates for neonatal deaths by the Institute of Health Metrics and Evaluation (IHME) for GBD2010 and the estimates of the United Nations are remarkably similar at the global level, with the estimates for the three major causes of neonatal deaths (preterm birth, neonatal infections, and intrapartum-related conditions) being within the uncertainty range of each other (Table 7). The slightly lower estimate by the IHME for preterm and intrapartum-related conditions may be counterbalanced by the higher proportion filed in "neonatal other," possibly due to variation in application of some specific ICD codes for more recently added but common diagnoses (e.g., intraventricular hemorrhage), which rely on four-digit codes in ICD, and which, without the use of four-digit codes, may be filed in the "other" category. If neonatal infections are grouped, then the IHME estimate is 750,000 and the UN estimate is 718,000 . Yet, the split for infection syndromes is very different in the two sets of estimates and highlights the challenges of clinical assignment of pneumonia compared with assignment of neonatal sepsis or meningitis, given overlapping symptoms (29). The inputs, and indeed the methods, between these two sets of estimates are broadly similar. However, the increased data availability for neonatal cause-of-death estimates while encouraging highlights the ongoing, major gaps for data on nonfatal outcomes. 


\section{Articles $\mid$ Blencowe et al.}

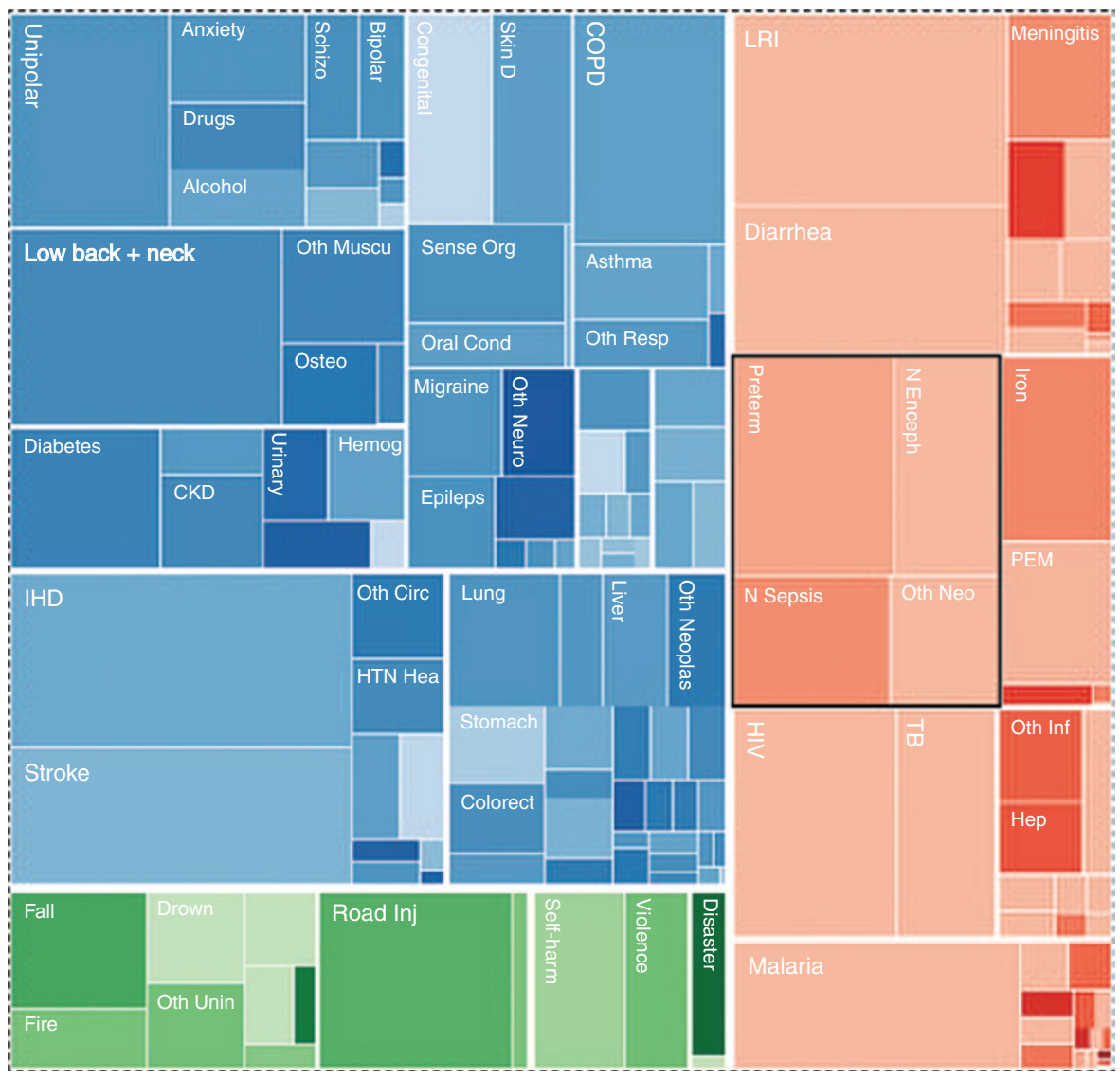

Figure 4. Global Burden of Disease (GBD2010) estimated distribution of the 2.5 billion disability-adjusted life years for 2010 for all age groups.

\section{Time Trends}

Overall, considering all conditions, GBD2010 highlighted four transitions from 1990 to 2010 (15): first, a demographic transition, with the overall burden shifting from children to adults; however, these results still highlight a big burden in terms of absolute numbers in neonatal conditions, with large country/ regional variation and a large unfinished agenda in terms of high mortality from many neonatal conditions, especially in low-income settings. Second, a disease transition, with a shift from communicable (which in GBD also includes maternal and neonatal disorders) to noncommunicable disease. However, in some regions, e.g., sub-Saharan Africa, the former are still very important and despite a $26 \%$ estimated reduction in the number of DALYs from neonatal conditions from 1990 to 2010, they still account for more than 200 million DALYs in 2010 (15). Third, a disability transition, with disability now accounting for a third of all DALYs globally and in some highincome countries, it is more important overall than premature mortality; however, for neonatal conditions, premature mortality accounts for almost all (95\%) DALYs, especially in lowincome settings. Improvement in quality of care is important in reducing both deaths and impairment and should be developed together. Fourth and finally, a risk transition, with a rapid change from poverty to lifestyle risk factors, as exemplified by the double burden of under- and overnutrition seen in many middle-income countries. However, some neonatal conditions occur, or may even increase, with rising socioeconomic levels, e.g., preterm birth, which is very high, for example, in the United States. The availability of specialized care for neonatal conditions at both Special Care and neonatal intensive care unit (NICU) levels may lag behind large societal economic improvements or may be provided but without sufficient quality.

Data to inform these morbidity estimates were limited and even more limited over time, hence caution should be applied when interpreting trend results. GBD2010 estimated time trends for all conditions including neonatal ones. Data to input into these conditions were challenging and increasingly so for older data to inform 1990 estimates. Due to data constraints around the reliability and comparability of the available data to provide time trends for some conditions, in the compartmental model, we only estimated time trend data for intrapartum-related conditions. Moving forward, it will be critical to ensure comparability in measurement and reporting to enable improved tracking of any real changes in outcome, avoiding measurement and case ascertainment artifacts.

\section{Limitations}

GBD2010 had a very wide scope and standard approaches across conditions were required; hence, the level of granularity that a specialist reader may desire was not always possible. In cases of data unavailability from both the literature and expert groups, some assumptions were applied by the estimation team, e.g., by assuming that the ratio YLL:YLD for "other neonatal conditions" was equal to the YLL:YLD ratio for preterm and intrapartum-related 
conditions or by back calculating the incidence of neonatal sepsis from the number of deaths and the uncertain case fatality rate. One such area where the standard approach used in GBD2010 may be more challenging for estimation of neonatal condition is the use of the "steady state" assumption. This assumption was used in GBD2010 to estimate prevalence of a condition across all ages and was applied to the data on incidence, case fatality, and impaired survival from 2010, along with the excess mortality to the whole population at all ages in 2010. This was done to enable the calculation of comorbidity and is a reasonable assumption in a condition whose incidence, duration, case fatality rate, and impaired survival do not vary substantially over time. However, this is not the case for neonatal conditions, e.g., a preterm baby born at $29 \mathrm{wk}$ gestation in 1945, if he/she survives, would be in the 65- to -69-y age group in 2010. Assuming the same neonatal survival for all ages as for a baby born in 2010 will overestimate the number of survivors in historical cohorts pre-NICU, even in a high-income country. Moreover, given major changes over time, GBD steady state assumptions may over- or underestimate the risk of impairment in survivors depending on the evolutionary stage of NICU. In view of this changing care and outcomes over time, in the subsequent articles in this supplement, we focus on incident cases in the year 2010.

In addition to the paucity of available data, substantial variation was found in the quality and comparability of many of the studies, especially when considering impairment outcomes over time, across settings, and with the absence of a uniform metric to assess disability. Many studies report outcomes using different assessment tools, applied at different ages, and by pooling different groups of babies at risk, limiting the comparability across studies. In addition, many studies report on the number in a given risk group with each of the given outcomes, e.g., number with cerebral palsy, number with visual impairment, or number with cognitive impairment, without giving any information on those with more than one impairment to allow estimation of the overall number of children with moderate to severe impairment. Ideally, all studies would have assessed children at the same age. Many studies also publish results of the assessment of the cohort at several points, e.g., at $2 \mathrm{y}$, at $6-8 \mathrm{y}$, and then in adolescence, in most cases, with increasing levels of loss to follow-up over time (38). We sought to balance the loss of data due to loss to followup with the ability to be able to predict long-term impairment and included only cohorts with minimum follow-up time of 18 mo; however, this may only be a moderate predictor of longterm outcomes, especially in preterm survivors (39). Where more than one assessment of a cohort was available, we used data from the primary school-aged assessment.

The GBD summary results have been published elsewhere (15), and an overview of the neonatal-specific methodology and results are presented in this article. The subsequent articles in this supplement (Table 2) (27-29,31,33) provide further details of the specific methodology and data inputs by condition for newborns advancing further from the data used in GBD2010, while noting some remaining important data limitations. We build on the lessons that we learnt out of GBD2010 to further refine the assumptions made and have updated the data inputs in the subsequent articles that provide estimates of number of impaired survivors for each condition for 2010 using a compartmental model. We provide a full description of the steps taken in terms of input parameters and process for the models. Our aim is that by providing the details in terms of numbers of incident cases, deaths, and long-term impaired survivors, the data will be more effectively used to inform planning of health, education, and social services and also be useful for improved data collection to better track these outcomes.

These estimates have presented substantial challenges in terms of limitations in the current data. The data gaps are not uniform across conditions, geography, and time. Substantial inequity is shown not only in terms of outcomes of these conditions but also in data to inform these outcomes. For example, preterm birth, which is common in high-income countries, has much more data globally than for neonatal infections in term babies, which are much more common in poor countries. Improving future estimates will require both improved methods of using the available data, for example, refining the modeling methods, and also, most crucially, improvements in data collection using consistent definitions and tools and from a wider range of sources and geographies.

\section{Conclusion}

The results of the GBD2010 work and the results of the compartmental models described in this supplement highlight the large burden that newborn conditions contribute to deaths and illhealth in populations throughout the world in 2010-even the data limitations cannot mask this, although they may particularly miss the impairment outcomes. Reducing neonatal mortality is still an important unfinished agenda in all settings. Our aim is to draw more attention to the growing importance of neonatal morbidity, the global burden of long-term impairment associated with these conditions, and the economic loss to families and nations, in addition to outlining the associated measurement challenges to improve data collection in the future. We hope that this publication will help engage the pediatric, obstetric, and public health communities to work together to strengthen programs, policies, and data to prevent and manage these conditions, in addition to aiding in development of services for those with impairment following neonatal and other insults.

\section{SUPPLEMENTARY MATERIAL}

Supplementary material is linked to the online version of the paper at http:// www.nature.com/pr

\section{STATEMENT OF FINANCIAL SUPPORT}

This article is published as part of a supplement sponsored by The Bill and Melinda Gates Foundation to the Child Health Epidemiology Reference Group through the US Fund for United Nations Children's Fund (UNICEF) and to Save the Children's Saving Newborn Lives program. A.C.L., H.B., and S.C. were supported through a grant from the Bill and Melinda Gates Foundation through the Child Health Epidemiology Reference Group. J.L. was funded by the Bill and Melinda Gates Foundation through Save the Children's Saving Newborn Lives program.

Disclosure: A.C.L. received grant support from U.S. Agency for International Development and the National Institutes of Health and has served as a consultant for Save the Children's Saving Newborn Lives program. The other authors declare no conflict of interest. 


\section{REFERENCES}

1. UNICEF. Childinfo - Monitoring the Situation of Children and Women, 2012. (www.childinfo.org).

2. Lozano R, Wang H, Foreman KJ, et al. Progress towards Millennium Development Goals 4 and 5 on maternal and child mortality: an updated systematic analysis. Lancet 2011;378:1139-65.

3. Lawn JE, Kinney MV, Black RE, et al. Newborn survival: a multi-country analysis of a decade of change. Health Policy Plan 2012;27:Suppl 3:iii6-iii28.

4. UNICEF. Committing to Child Survival: A promise renewed, 2012.

5. Independent Expert Review Group (iERG) on Information and Accountability for Women's and Children's Health 2012 Every Woman Every Child: from commitments to action. World Health Organization. (http://www. who.int/woman_child_accountability/ierg/reports/en/).

6. Liang J, Mao M, Dai L, et al. Neonatal mortality due to preterm birth at 28-36 weeks' gestation in China, 2003-2008. Paediatr Perinat Epidemiol 2011;25:593-600.

7. 2012 Born Too Soon: The Global Action Report on Preterm Birth. Howson CP, Kinney MV, Lawn JE, eds. March of Dimes, PMNCH, Save the Children, World Health Organization. New York, 2012 (http://www.who.int/ pmnch/media/news/2012/preterm_birth_report/en/index1.html).

8. Mwaniki MK, Atieno M, Lawn JE, Newton CR. Long-term neurodevelopmental outcomes after intrauterine and neonatal insults: a systematic review. Lancet 2012;379:445-52.

9. Lawn JE, Cousens S, Zupan J; Lancet Neonatal Survival Steering Team. 4 million neonatal deaths: when? Where? Why? Lancet 2005;365:891-900.

10. Liu L, Johnson HL, Cousens S, et al.; Child Health Epidemiology Reference Group of WHO and UNICEF. Global, regional, and national causes of child mortality: an updated systematic analysis for 2010 with time trends since 2000. Lancet 2012;379:2151-61.

11. Black RE, Cousens S, Johnson HL, et al.; Child Health Epidemiology Reference Group of WHO and UNICEF. Global, regional, and national causes of child mortality in 2008: a systematic analysis. Lancet 2010;375:1969-87.

12. Mathers CD, Lopez AD, Murray CJL. The burden of disease and mortality by condition: data, methods, and results for 2001. In: Lopez AD, Mathers CD, Ezzati M, Jamison DT, Murray CJL, eds. Global Burden of Disease and Risk Factors. The International Bank for Reconstruction and Development/ The World Bank Group, Washington: DC, 2006.

13. Murray CJ, Lopez AD. Global mortality, disability, and the contribution of risk factors: Global Burden of Disease Study. Lancet 1997;349:1436-42.

14. Lozano R, Naghavi M, Foreman K, et al. Global and regional mortality from 235 causes of death for 20 age groups in 1990 and 2010: a systematic analysis for the Global Burden of Disease Study 2010. Lancet 2012;380:2095-128.

15. Murray CJ, Vos T, Lozano R, et al. Disability-adjusted life years (DALYs) for 291 diseases and injuries in 21 regions, 1990-2010: a systematic analysis for the Global Burden of Disease Study 2010. Lancet 2012;380:2197-223.

16. Vos T, Flaxman AD, Naghavi M, et al. Years lived with disability (YLDs) for 1160 sequelae of 289 diseases and injuries 1990-2010: a systematic analysis for the Global Burden of Disease Study 2010. Lancet 2012;380:2163-96.

17. Lawn JE, Blencowe H, Pattinson R, et al.; Lancet's Stillbirths Series steering committee. Stillbirths: Where? When? Why? How to make the data count? Lancet 2011;377:1448-63.

18. United Nations Population Division 2010. World Population Prospects. (http://esa.un.org/wpp/Documentation/pdf/WPP2010_Volume-I_ Comprehensive-Tables.pdf).

19. Murray CJ, Ezzati M, Flaxman AD, et al. GBD 2010: design, definitions, and metrics. Lancet 2012;380:2063-6.

20. Burden of disease research unit. Medical research council. Rapid mortality surveillance report, 2011. (http://www.mrc.ac.za/bod/RapidMortality2011.pdf.).

21. Lives Saved Tool (LiST). (http://www.futuresinstitute.org/spectrum. aspx).

22. Walsh-Sukys MC, Fanaroff AA. Perinatal Services and Resources. Franaroff AA, Martin RI, eds. Neonatal Perinatal Medicine, St Louis: Mosby, 1997;13-22.

23. Salomon JA, Vos T, Hogan DR, et al. Common values in assessing health outcomes from disease and injury: disability weights measurement study for the Global Burden of Disease Study 2010. Lancet 2012;380:2129-43.

24. Hagberg B, Hagberg G. The changing panorama of cerebral palsy-bilateral spastic forms in particular. Acta Paediatr Suppl 1996;416:48-52.
25. Badawi N, Felix JF, Kurinczuk JJ, et al. Cerebral palsy following term newborn encephalopathy: a population-based study. Dev Med Child Neurol 2005;47:293-8.

26. Barendregt JJ, Bonneux L, Van der Maas PJ. DALYs: the age-weights on balance. Bull World Health Organ 1996;74:439-43.

27. Blencowe H, Lee AC, Cousens S, et al. Preterm birth-associated neurodevelopmental impairment estimates at regional and global levels for 2010. Pediatr Res 2013 (this issue).

28. Lee AC, Kozuki N, Blencowe H, et al. Intrapartum-related encephalopathy incidence and impairment at regional and global levels for 2010 with trends from 1990. Pediatr Res 2013 (this issue).

29. Seale AC, Blencowe $H$, Zaidi A, et al. Neonatal severe bacterial infection impairment estimates in South Asia, sub-Saharan Africa, and Latin America for 2010. Pediatr Res 2013 (this issue).

30. Edmond K, Clark A, Korczak VS, Sanderson C, Griffiths UK, Rudan I. Global and regional risk of disabling sequelae from bacterial meningitis: a systematic review and meta-analysis. Lancet Infect Dis 2010;10:317-28.

31. Bhutani VK, Zipursky A, Blencowe H, et al. Neonatal hyperbilirubinemia and Rhesus disease of the newborn: incidence and impairment estimates for 2010 at regional and global levels. Pediatr Res 2013 (this issue).

32. WHO 2004 ICD-10: international statistical classificiation of diseases and related health problems: tenth revision. 2nd edn, Geneva: Switzerland.

33. Blencowe H, Lawn JE, Vazquez T, Fielder A, Gilbert C. Preterm-associated visual impairment and estimates of retinopathy of prematurity at regional and global levels for 2010. Pediatr Res 2013 (this issue).

34. Institute of Health Metrics Evaluation. (http://www.healthmetricsandevaluation.org/tools/data-visualizations.).

35. Cousens S, Blencowe H, Stanton C, et al. National, regional, and worldwide estimates of stillbirth rates in 2009 with trends since 1995: a systematic analysis. Lancet 2011;377:1319-30.

36. Jamison DT, Shahid-Salles SA, Jamison J, Lawn JE, Zupan J. Incorporating Deaths Near the Time of Birth into Estimates of the Global Burden of Disease. In: Lopez AD, Mathers CD, Ezzati M, Jamison DT, Murray CJL, eds. Global Burden of Disease and Risk Factors. The International Bank for Reconstruction and Development/The World Bank Group, Washington: DC, 2006.

37. Froen JF, Cacciatore J, McClure EM, et al. Stillbirths: why they matter. Lancet 2011;377:1353-66.

38. Tin W, Fritz S, Wariyar U, Hey E. Outcome of very preterm birth: children reviewed with ease at 2 years differ from those followed up with difficulty. Arch Dis Child Fetal Neonatal Ed 1998;79:F83-87.

39. Roberts G, Anderson PJ, Doyle LW. The stability of the diagnosis of developmental disability between ages 2 and 8 in a geographic cohort of very preterm children born in 1997. Arch Dis Child 2010;95:786-90.

40. UNICEF. The State of the World's Children, 2011. (http://www.unicef.org/ sowc2011/pdfs/SOWC-2011-Main-Report_EN_02092011.pdf).

41. United Nations 2011 Millennium Development Goals Indicators. (http://mdgs.un.org/unsd/mdg/Resources/Static/Products/Progress2011/11-31339\%20\%28E\%29\%20MDG\%20Report\%202011_ Book\%20LR.pdf).

42. The World Health Organization 2011 Global Health Atlas. (http://apps who.int/globalatlas/).

43. The World Health Organization 2011 National Health Accounts. (http:// www.who.int/nha/en/).

44. Pitt C, Greco G, Powell-Jackson T, Mills A. Countdown to 2015: assessment of official development assistance to maternal, newborn, and child health, 2003-08. Lancet 2010;376:1485-96.

45. Knippenberg R, Lawn JE, Darmstadt GL, et al. Systematic scaling up of neonatal care in countries. Lancet 2005;365:1087-98.

46. Foreman KJ, Lozano R, Lopez AD, Modeling causes of death: an integrated approach using CODEm. Popul Health Metr 2012;10:1.

47. Blencowe H, Cousens S, Oestergaard MZ, et al. National, regional, and worldwide estimates of preterm birth rates in the year 2010 with time trends since 1990 for selected countries: a systematic analysis and implications. Lancet 2012;379:2162-72.

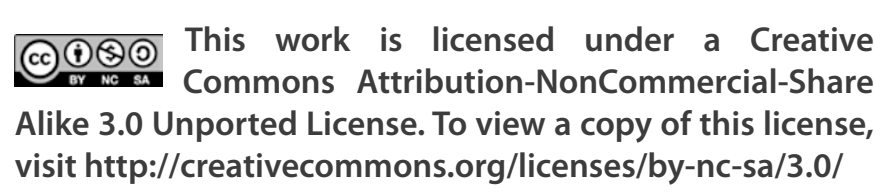

